\title{
Treatment of rheumatoid arthritis in the USA:
} premature use of tumor necrosis factor inhibition

This article was published in the following Dove Press journal: Open Access Rheumatology: Research and Reviews

\section{James R O'Dell' Stanley B Cohen ${ }^{2}$ J Carter Thorne ${ }^{3}$ Joel Kremer ${ }^{4}$}

'Department of Rheumatology, Division of Rheumatology and Immunology, University of Nebraska Medical Center and the Omaha VA, Omaha, NE, USA; ${ }^{2}$ Department of Internal Medicine, Metroplex Clinical Research Center, University of Texas Southwestern Medical School, Dallas, TX, USA; ${ }^{3}$ Division of Rheumatology, University of Toronto, Southlake Regional Health Centre, Toronto, ON, Canada; ${ }^{4}$ The Center for Rheumatology, Albany Medical College, Albany, NY, USA
Correspondence: James R O'Dell Division of Rheumatology and Immunology, University of Nebraska Medical Center, 983025 Nebraska Medical Center, Omaha, NE 68198-3025, USA

$\mathrm{Tel}+\mathrm{I} 4025597288$

Fax + I 4025596788

Email jrodell@unmc.edu
Purpose: The objective of this study was to assess the treatment for patients with rheumatoid arthritis (RA) in the USA.

Patients and methods: This study entailed analysis of claims data for patients with RA who initiated treatment with oral methotrexate (MTX) or a biologic in $2009(n=48,910)$ or 2012 ( $\mathrm{n}=107,636)$ and had follow-up for 4 years (2009 cohort) or 2 years (2012 cohort).

Results: A biologic was initiated before MTX for $27 \%$ of the 2009 cohort and $36 \%$ of the 2012 cohort. Concomitant use of MTX and a biologic declined from $74.1 \%$ ( 2009 cohort) to $45.4 \%$ (2012 cohort).

Conclusion: MTX is underused in the treatment of RA in the USA.

Keywords: biologic, claims, methotrexate, tumor necrosis factor

\section{Introduction}

Methotrexate (MTX) is the anchor drug to treat rheumatoid arthritis (RA). ${ }^{1,2}$ Guidelines of the American College of Rheumatology (ACR) and the European League Against Rheumatism (EULAR) recommend MTX as first-line therapy. ${ }^{1,2}$ The ACR guidelines recommend biologic agents (with a tumor necrosis factor inhibitor [TNFi] as the first choice) be added for patients whose disease activity remains moderate or high despite treatment with a synthetic disease-modifying antirheumatic drug (DMARD). ${ }^{2}$ EULAR recommendations also state that biologics (the first choice is a TNFi) be reserved for patients with insufficient responses to MTX or other synthetic DMARDs. ${ }^{1}$ Although these guidelines are generally accepted, some believe that initial use of a TNFi is clinically superior to and more cost-effective than initial use of MTX, ${ }^{3}$ and that biologics, but not synthetic DMARDs, reduce radiographic progression in patients with RA. ${ }^{4}$ Such statements are not supported by data and are contradicted by results of systematic reviews and meta-analyses of clinical literature. ${ }^{5,6}$

Surveys and claims analyses have produced conflicting results regarding the use of biologics as initial DMARD treatment in RA. A survey of physicians focused on treatment of newly diagnosed patients indicated that $6 \%$ would use a TNFi as initial DMARD treatment. ${ }^{7}$ In contrast, claims analyses covering the period from 2006 to 2009 indicated that $10-15 \%$ of patients with RA initiated DMARD treatment with a biologic agent. ${ }^{8,9}$

Many patients with RA do not continue MTX when treatment with a biologic is initiated. ${ }^{9}$ Treatment guidelines state that TNFi should be combined with MTX in patients with inadequate responses to MTX and/or other conventional DMARDs. ${ }^{1}$ 
However, a previous claims analysis suggests that this is not done in approximately $30 \%$ of patients. ${ }^{9}$

The objectives of the present study were to determine the rates of biologic use among patients with no prior exposure to MTX who initiated biologic therapy for RA in either 2009 or 2012 and to delineate the percentage of patients for whom MTX was combined with a biologic during initial treatment or when the patient was switched to a biologic.

\section{Materials and methods}

\section{Data source}

Data were extracted from Symphony Health Solutions Integrated Dataverse, which contains information from medical, hospital, and prescription health care claims for approximately 274 million USA patients. Patient-specific information was de-identified to comply with the Health Insurance Portability and Accountability Act and encrypted with unique identifiers for longitudinal tracking. Approval from an institutional review board was not required for this claims analysis, and no patient identification was linked to any of the data evaluated.

\section{Data extraction and study cohorts}

Patients diagnosed with RA (ICD-9 codes 714.0 and 714.30) and who were naïve to MTX treatment, defined by its absence from claims throughout a 1-year look-back period, were included.

Patients were grouped into 1 of 2 cohorts. The "2009 cohort" consisted of patients who initiated MTX or a biologic in 2009 and had at least 1 RA-related claim in each year of the study. The "2012 cohort" comprised patients who initiated MTX or a biologic in 2012 and had at least 1 RA-related claim in each subsequent year of the study. The latter cohort was used to compare prescribing patterns for patients diagnosed in 2009 with those for patients diagnosed in 2012. All patients were followed through the end of 2014, with tracking of all medical, hospital, and prescription claims.

\section{Coding}

The National Drug Codes and the Healthcare Common Procedure Coding System were used to identify MTX and biologic products (abatacept, adalimumab, anakinra, certolizumab, etanercept, golimumab, infliximab, rituximab, and tocilizumab) from the claims database.

\section{Comorbidities}

Comorbidities and prescription treatments were identified using ICD-9 codes, Healthcare Common Procedure Coding System, and National Drug Codes. Comorbidities were determined by the presence of ICD-9 codes submitted at any time during the study period.

\section{Data analysis}

Means, medians, and standard deviations were calculated for each cohort and each variable of interest. Differences between groups were analyzed using independent $t$-tests for continuous measures and chi-square tests for categorical values. $P$ values $<0.05$ were considered significant.

\section{Results \\ Subjects}

The study included 48,910 patients who initiated treatment with MTX or a biologic in 2009 and 107,636 who started treatment in 2012. The major reason for the large numeric difference is that 4 years of follow-up were required for the 2009 cohort but only 2 years for the 2012 cohort. Demographic and clinical characteristics are summarized in Table 1. The prevalences of diabetes, ischemic cardiovascular disease, and gastrointestinal disease were higher in the 2009 cohort.

\section{Initiation of treatment with a biologic agent}

A biologic agent was the initial treatment for $27.1 \%$ of patients in 2009 and for $35.6 \%$ of patients in $2012(P<0.0001)$ (Figure 1A). The cohorts differed slightly in exposure to non-MTX DMARDs prior to biologic use (Table 1). A significantly higher percentage of patients in the 2012 cohort received a non-MTX DMARD before treatment with a biologic agent $(25.4 \%$ vs $15.3 \% ; P<0.0001)$. However, even when these patients were excluded from the analysis, the between-group difference in use of a biologic before MTX remained significant $(24.0 \%$ vs $29.1 \% ; P<0.0001)$.

\section{Use of MTX in addition to biologic treatment}

Among patients who started biologic treatment without prior MTX, 39.2\% of this subset of the 2009 cohort and $38.4 \%$ of the 2012 cohort initiated therapy with MTX and a biologic concomitantly $(P>0.05)$ (Figure $1 \mathrm{~B})$. Among patients initially treated with oral MTX who received a biologic subsequently, $74.1 \%$ of this subset of the 2009 cohort and only $45.4 \%$ of the 2012 cohort continued to receive MTX $(P<0.0001)$ (Figure 1C). This change in treatment pattern did not relate to a difference between cohorts in anti-TNF treatment: $52.3 \%$ of patients in the 2009 cohort who switched from oral MTX to a biologic received adalimumab, certolizumab, golimumab, or infliximab, as did $50.2 \%$ of the 2012 cohort. 
Table I Demographic and clinical characteristics of study cohorts

\begin{tabular}{|c|c|c|c|c|}
\hline & \multicolumn{2}{|l|}{2009 cohort } & \multicolumn{2}{|l|}{2012 cohort } \\
\hline & $\begin{array}{l}\text { Initiated with } \\
\text { biologic }(n=13,270)\end{array}$ & $\begin{array}{l}\text { Initiated with oral } \\
\text { MTX }(n=35,640)\end{array}$ & $\begin{array}{l}\text { Initiated with } \\
\text { biologic }(n=38,309)\end{array}$ & $\begin{array}{l}\text { Initiated with } \\
\text { oral MTX }(n=69,327)\end{array}$ \\
\hline Age, year, mean (median) & $59(60)$ & $62(62)$ & $57(59)$ & $57(59)$ \\
\hline \multicolumn{5}{|l|}{ Gender, \% } \\
\hline Male & 18 & 22 & 15 & 17 \\
\hline Female & 82 & 78 & 85 & 83 \\
\hline \multicolumn{5}{|l|}{ Race/ethnicity, \% } \\
\hline African American & 8 & 10 & 8 & 8 \\
\hline Caucasian & 63 & 58 & 62 & 58 \\
\hline Hispanic & 7 & 7 & 7 & 7 \\
\hline Missing/uncoded & 22 & 24 & 23 & 21 \\
\hline \multicolumn{5}{|l|}{ Comorbidities, \% } \\
\hline Ischemic CVD & 18 & 16 & 12 & 12 \\
\hline Diabetes & 29 & 26 & 25 & 24 \\
\hline Gl disease & 53 & 47 & 41 & 39 \\
\hline \multicolumn{5}{|c|}{ Treatment with non-MTX DMARD, \%* } \\
\hline Sulfasalazine & 3.1 & 1.5 & 4.7 & 2.9 \\
\hline Hydroxychloroquine & 7.6 & 4.1 & 7.5 & 10.1 \\
\hline Leflunomide & 4.6 & 1.3 & 13.2 & 2.2 \\
\hline
\end{tabular}

Note: *Data were available for 20,04I patients who started MTX in 2009 and for 18,989 patients who started oral MTX in 2012.

Abbreviations: CVD, cardiovascular disease; DMARD, disease-modifying antirheumatic drug; GI, gastrointestinal; MTX, methotrexate.

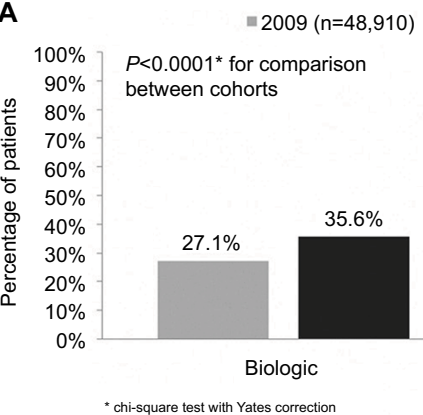

C

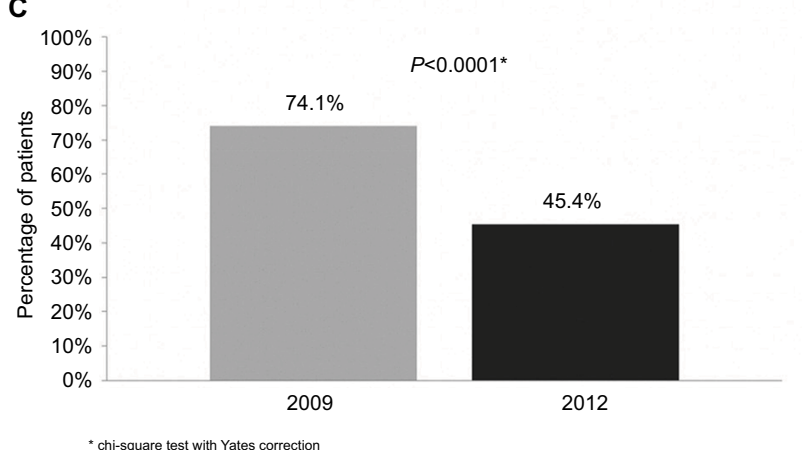

- $2012(n=107,636)$

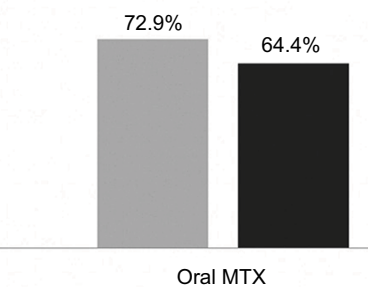

Oral MTX

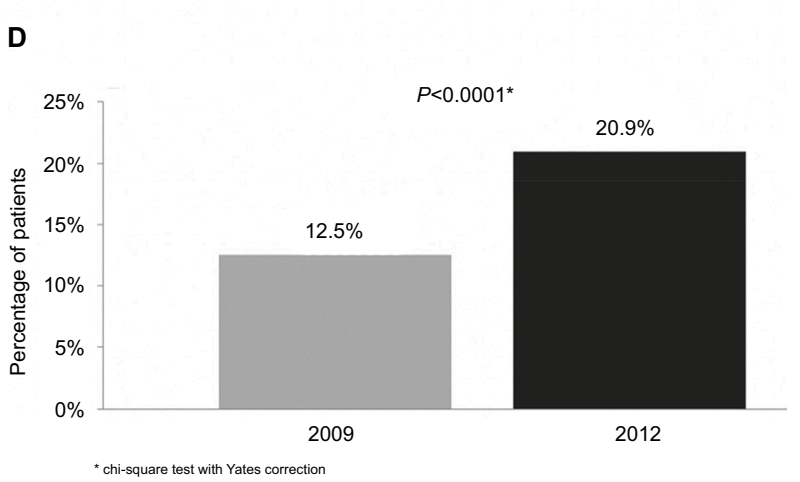

B

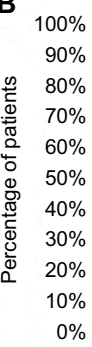

$39.2 \%$

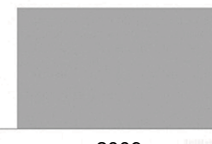

2009

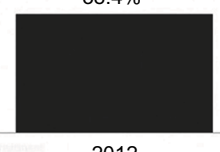

2012

D

Figure I (A) Percentage of patients who initiated therapy with a biologic or MTX. (B) Use of MTX in patients who initiated treatment with a biologic. (C) Use of MTX in patients who received a biologic following treatment with oral MTX. (D) Percentage of patients who switched to SC MTX after failure with oral MTX treatment. Abbreviations: MTX, methotrexate; SC, subcutaneous.

\section{Use of subcutaneous (SC) MTX}

There was significantly increased use of SC MTX from 2009 to 2012. Of the 35,640 patients who initiated oral MTX in $2009,20,041(56.2 \%)$ were switched from it during the subsequent 5 years. Of these, 2,513 (12.5\%) were switched to SC MTX. In the 2012 cohort, 69,327 patients started oral MTX, and 18,989 (27.4\%) were switched from this treatment in the ensuing 2 years. Of these, 3,976 (20.9\%) were 
switched to SC MTX $(P<0.0001$ vs SC MTX use in the 2009 cohort) (Figure 1D).

\section{Discussion}

The data indicate that in the USA, a large percentage of patients with RA receive a biologic without prior treatment with MTX and that this approach is increasing. Additionally, for patients who start a biologic without prior MTX, clinicians are not uniformly prescribing concomitant MTX, and again, this practice is increasing, observed in only $45.4 \%$ of patients from the 2012 cohort vs $74.1 \%$ of the 2009 cohort. These trends are alarming with regard to optimal clinical and certainly economical care.

Compared with earlier claims analyses, ${ }^{9,10}$ the present study indicates that there may have been a 2- to 3-fold increase in the use of biologic DMARDs without prior MTX in patients with RA. The reasons for this are not clear; guidelines for the initial treatment of RA did not change substantially during the time these analyses were conducted. ${ }^{2,11,12}$

Concurrent use of MTX and a TNFi is viewed as the standard of care for patients with RA whose disease activity continues despite MTX treatment, ${ }^{13}$ and this is consistent with results indicating better clinical responses to TNFi plus MTX vs monotherapy. ${ }^{14}$ Our analysis indicated that this guidance is not followed by many clinicians and is consistent with other results indicating underuse of MTX among patients receiving biologics. ${ }^{9,15}$

While not the primary focus of the study and on a brighter note, our analysis indicated that between 2009 and 2012, significantly more patients who initially received oral MTX were switched to SC MTX. This change in treatment patterns is consistent with results indicating significant clinical improvements with SC MTX in patients who discontinued the oral drug because of intolerance or inadequate efficacy. ${ }^{16-18}$ Although the use of SC MTX, which has better bioavailability and is better tolerated than oral MTX, is still much less than optimal, it at least appears to be increasing.

An obvious strength of the study is the very large data set (274 million lives). Since this is a claims analysis, a significant limitation is that the reasons for change to or adding another therapy are not known. The analysis used a 1-year look-back period, and this demonstrated that $15 \%$ of patients in the 2009 cohort and $25 \%$ of those in the 2012 cohort had received a non-MTX DMARD prior to the first treatment with either MTX or a biologic. Exclusion of these patients from the analysis did not change the conclusion that significantly more patients initiated a biologic prior to MTX treatment in the 2012 cohort vs the 2009 group. However, given that the look-back period was only 1 year, it is possible that some patients received MTX prior to the beginning of this period. Finally, it is important to emphasize that these results apply only to practice in the USA. It would be very interesting to determine if the trends reported have occurred in other countries.

\section{Conclusion}

This claims analysis shows that many patients with RA receive a biologic agent without prior treatment with MTX or any other synthetic DMARD and that this approach to treatment increased from 2009 to 2012 . MTX is also underused in patients receiving a biologic agent, either as their first DMARD or after exposure to oral MTX. This suggests that many patients with RA in the USA are not receiving the maximum benefit of MTX, the most-effective conventional DMARD. Findings from this analysis raise major concerns about the quality and value of care provided for patients with RA in the USA.

\section{Acknowledgment}

The authors acknowledge the support of Robert W Rhoades, $\mathrm{PhD}$, in development of the manuscript.

\section{Author contributions}

All authors contributed toward data analysis, drafting and revising the paper and agree to be accountable for all aspects of the work

\section{Disclosure}

Dr O'Dell has been a consultant for Medac Pharma, BristolMeyers Squibb, Eli Lilly and Company, Crescendo Bioscience, Coherus BioSciences, and GlaxoSmithKline. Dr Cohen is the medical director of Metroplex Clinical Research Center, and the center has received clinical trial grants from AbbVie, Amgen, Ardea Biosciences, Astellas Pharma Global Development, AstraZeneca, Boehringer Ingelheim, Biogen Idec, Bristol-Myers Squibb, Celgene Corporation, Eli Lilly and Company, Flexion, Genentech, GlaxoSmithKline, Hoffmann-La Roche Inc., Janssen, MedImmune, Merck, Novartis, Pfizer Inc., Procter \& Gamble Pharmaceuticals, Regeneron Pharmaceuticals, Roche, Sanofi-Aventis, UCB, and Vertex Pharmaceuticals. He has been a consultant for Amgen Inc., Boehringer Ingelheim, Biogen Idec, BristolMyers Squibb, Celltrion, Centocor Ortho Biotech Inc., Crescendo Bioscience, Flexion, Genentech, Pfizer Inc., Roche, and Sandoz. Dr Thorne has participated in advisory boards for AbbVie, Amgen, Celgene, Sanofi Genzyme, Hospira, 
Janssen, Eli Lilly and Company, Medexus, Medac Pharma, Merck, Novartis, and Pfizer. He has been a consultant for AbbVie, Centocor, Sanofi Genzyme, Hospira, Eli Lilly and Company, Medexus, Medac Pharma, and Pfizer. He has been a speaker for Medexus and Medac Pharma. He has received IIS funding from AbbVie, Amgen, and Pfizer, and RCT funding from AbbVie, Celgene, CaREBiodam, Novartis, and Pfizer. Dr Kremer has received research support from AbbVie, Eli Lilly and Company, Novartis, and Pfizer. He has served as a consultant for AbbVie, Bristol-Meyers Squibb, GlaxoSmithKline, Eli Lilly and Company, and Pfizer. He is employed by Corrona. The authors report no other conflicts of interest in this work.

\section{References}

1. Smolen JS, Landewé R, Bijlsma J, et al. EULAR recommendations for the management of rheumatoid arthritis with synthetic and biological disease-modifying antirheumatic drugs: 2016 update. Ann Rheum Dis. 2017;76(6):960-977.

2. Singh JA, Saag KG, Bridges SL Jr, et al. 2015 American College of Rheumatology guideline for the treatment of rheumatoid arthritis. Arthritis Rheumatol. 2016;68(1):1-26.

3. Spalding JR, Hay J. Cost effectiveness of tumour necrosis factor-alpha inhibitors as first-line agents in rheumatoid arthritis. Pharmacoeconomics. 2006;24(12):1221-1232.

4. Upchurch KS, Kay J. Evolution of treatment for rheumatoid arthritis. Rheumatology (Oxford). 2012;Suppl 6:vi28-vi36.

5. Graudal N, Hubeck-Graudal T, Faurschou M, Baslund B, Jürgens G. Combination therapy with and without tumor necrosis factor inhibitors in rheumatoid arthritis: a meta-analysis of randomized trials. Arthritis Care Res (Hoboken). 2015;67(11):1487-1495.

6. Gómez-Reino J. Biologic monotherapy as initial treatment in patients with early rheumatoid arthritis. Rheumatology (Oxford). 2012;Suppl 5:v31-v37.

7. Glauser TA, Ruderman EM, Kummerle D, Kelly S. Current practice patterns and educational needs of rheumatologists who manage patients with rheumatoid arthritis. Rheumatol Ther. 2014;1(1):31-44.
8. Desai RJ, Rao JK, Hansen RA, Fang G, Maciejewski ML, Farley JF. Predictors of treatment initiation with tumor necrosis factor- $\alpha$ inhibitors in patients with rheumatoid arthritis. J Manag Care Spec Pharm. 2014;20(11):1110-1120.

9. Zhang J, Xie F, Delzell E, et al. Trends in the use of biologic agents among rheumatoid arthritis patients enrolled in the US Medicare program. Arthritis Care Res (Hoboken). 2013;65(11):1743-1751.

10. Yazici Y, Shi N, John A. Utilization of biologic agents in rheumatoid arthritis in the United States: analysis of prescribing patterns in 16,752 newly diagnosed patients and patients new to biologic therapy. Bull NYU Hosp Jt Dis. 2008;66(2):77-85.

11. Saag KG, Teng GG, Patkar NM, et al; American College of Rheumatology. American College of Rheumatology 2008 recommendations for the use of nonbiologic and biologic disease-modifying antirheumatic drugs in rheumatoid arthritis. Arthritis Rheum. 2008;59(6):762-784.

12. Singh JA, Furst DE, Bharat A, et al. 2012 update of the 2008 American College of Rheumatology recommendations for the use of disease-modifying antirheumatic drugs and biologic agents in the treatment of rheumatoid arthritis. Arthritis Care Res (Hoboken). 2012;64(5):625-639.

13. Emery P, Sebba A, Huizinga TW. Biologic and oral disease-modifying antirheumatic drug monotherapy in rheumatoid arthritis. Ann Rheum Dis. 2013;72(12):1897-1904.

14. Buckley F, Finckh A, Huizinga TW, Dejonckheere F, Jansen JP. Comparative efficacy of novel DMARDs as monotherapy and in combination with methotrexate in rheumatoid arthritis patients with inadequate response to conventional DMARDs: a network meta-analysis. J Manag Care Spec Pharm. 2015;21(5):409-423.

15. Engel-Nitz NM, Ogale S, Kulakodlu M. Use of anti-tumor necrosis factor therapy: a retrospective study of monotherapy and adherence to combination therapy with non-biologic disease-modifying antirheumatic drugs. Rheumatol Ther. 2015;2(2):127-139.

16. Hameed B, Jones H. Subcutaneous methotrexate is well tolerated and superior to oral methotrexate in the treatment of rheumatoid arthritis Int J Rheum Dis. 2010;13(4):e83-e84.

17. Li D, Yang Z, Kang P, Xie X. Subcutaneous administration of methotrexate at high doses makes a better performance in the treatment of rheumatoid arthritis compared with oral administration of methotrexate: a systematic review and meta-analysis. Semin Arthritis Rheum. 2016;45(6):656-662.

18. Bianchi G, Caporali R, Todoerti M, Mattana P. Methotrexate and rheumatoid arthritis: current evidence regarding subcutaneous versus oral routes of administration. Adv Ther. 2016;33(3):369-378.
Open Access Rheumatology: Research and Reviews

\section{Publish your work in this journal}

Open Access Rheumatology: Research and Reviews is an international, peerreviewed, open access journal publishing original research, reports, editorials, reviews and commentaries on all aspects of clinical and experimental rheumatology in the clinic and laboratory including the following topics: Pathology, pathophysiology of rheumatological diseases; Investigation, treatment and management of rheumatological diseases; Clinical trials and novel pharmacologi$\mathrm{cal}$ approaches for the treatment of rheumatological disorders. The manuscript management system is completely online and includes a very quick and fair peer-review system, which is all easy to use. Visit http://www.dovepress.com/ testimonials.php to read real quotes from published authors. 